\title{
A Comparative Evaluation of the Voluntary Medical Male Circumcision Program for Seke and Goromonzi Districts, Mashonaland East Province, Zimbabwe, 2017
}

\section{Hamufare Mugauri ${ }^{1}$, Owen Mugurungi², Gerald Shambira ${ }^{1}$, Tsitsi Juru ${ }^{1}$, Notion Tafara Gombe ${ }^{1}$, Mufuta Tshimanga ${ }^{1}$}

${ }^{1}$ Department of Community Medicine, University of Zimbabwe, Harare, Zimbabwe

${ }^{2}$ Ministry of Health and Child Care, Harare, Zimbabwe

Email:dumiwaboka@gmail.com, atp.director@gmail.com, gshambira@yahoo.com, *tsitsijuru@gmail.com, gombent@yahoo.com, tshimangamufuta@gmail.com

How to cite this paper: Mugauri, $\mathrm{H}$., $\mathrm{Mu}-$ gurungi, O., Shambira, G., Juru, T., Gombe, N.T. and Tshimanga, M. (2017) A Comparative Evaluation of the Voluntary Medical Male Circumcision Program for Seke and Goromonzi Districts, Mashonaland East Province, Zimbabwe, 2017. Open Journal of Preventive Medicine, 7, 138-150.

https://doi.org/10.4236/ojpm.2017.77011

Received: May 18, 2017

Accepted: July 22, 2017

Published: July 25, 2017

Copyright $\odot 2017$ by authors and Scientific Research Publishing Inc. This work is licensed under the Creative Commons Attribution International License (CC BY 4.0).

http://creativecommons.org/licenses/by/4.0/

\section{(c) (i) Open Access}

\begin{abstract}
Background: In 2009, Zimbabwe incorporated Voluntary Medical Male Circumcision (VMMC) to a consortium of measures to eliminate HIV transmission by 2030 . Seke and Goromonzi districts simultaneously commenced implementing VMMC. These districts have comparable population, geography, and support yet scored varied performances. Cumulatively, (2009-2016) Seke achieved $83 \%$ while Goromonzi achieved 15\% of set circumcision targets. We compared the performance of the VMMC program in the 2 districts. Methodology: A process evaluation was conducted modelled on a logical framework. Interviewer-administered questionnaires and checklists were used to collect data. Epi info7 was used to generate frequencies and proportions. Results: Three health facilities in Seke and four in Goromonzi were implementing VMMC. Material resources were maintained at three months buffer stock and human resources equitably distributed between the two districts. Additional support (three nurses), from the national army, was received by Seke, and management provided vehicle support for program activities. Goromonzi conducted half of the targeted mobilisations (6/12) and Seke 12/12. Similar amounts of financial support were simultaneously disbursed. Seke circumcised 99.5\% (4716) and Goromonzi 48.5\% (2372) of annual targets. Adverse reactions were $0.04 \%$ (2) for Seke and $2.3 \%$ (55) for Goromonzi for same period with no review meetings conducted. Seke participants attributed performance to effective demand creation $(22 ; 100 \%)$, effective coordination (20; 90.9\%) and management support (21; 95.5\%). Goromonzi participants cited
\end{abstract}


delayed payments $(20 ; 90.9 \%)$, lack of active leadership involvement in planning and execution $(14 ; 63.6 \%)$ and weak mobilisations $(11 ; 50 \%)$ to have worked against the program. Conclusion: Effective demand creation and coordination, manpower boost and leadership support enhanced VMMC program performance for Seke and was therefore recommended for Goromonzi. Resource availability did not translate to performance in Goromonzi where lack of active leadership involvement in planning and execution, weak mobilisations resulted in poor results. Robust demand creation strategies were suggested for both districts.

\section{Keywords}

Male Circumcision, Adverse Events, Comparative, Program Evaluation

\section{Introduction}

Compelling evidence from three randomised, controlled clinical trials obtained in March 2007 informed WHO and UNAIDS to issue recommendations on male circumcision to be in cooperated as part of a comprehensive HIV prevention package [1]. The clinical trials, conducted in Kenya, South Africa and Uganda, proffered evidence on male circumcision's ability to reduce the risk of heterosexually acquired HIV infection in men by up to 60\% [2] [3] [4].

In 2010, Voluntary Medical Male Circumcision (VMMC) was officially launched as a core HIV prevention program in Zimbabwe, following a two-phase pilot [5]. The introduction of the program was guided by a national policy on VMMC, as well as the 2010 Strategy for Safe Male Circumcision in Zimbabwe [5]. However, the rate of scale-up was slow between 2010 and 2012; at the end of 2012, approximately eight percent of the target VMMCs had been conducted. This led to the revision of the national targets as well as of the timelines-from 2015 to a 2018 score-line. While Zimbabwe had only one VMMC implementing partner since 2009 (Population Services International), the entrance of the ZAZIC consortium (ZACH, ZICHIRE and I-TECH) and the Integrated Support Programme (ISP) as additional implementing partners brought diversity to the VMMC implementation landscape [6].

Zimbabwe was particularly identified, in 2013, as one of the fourteen priority countries for the scale-up of VMMC owing to a high HIV prevalence that was above $15 \%$ then, coupled with a historically low prevalence of male circumcision [7]. Because HIV remains a major public health challenge in Zimbabwe, the Ministry of Health and Child Care (MOHCC) adopted and prioritised VMMC as a national strategy to add to the suite of interventions designed to end HIV and AIDS by 2030 [6]. Informed by robust impact modelling, Zimbabwe set out to circumcise 1.27 million males between the ages of 15 and 29 years between 2009 and 2015. The scale up is anticipated to yield an estimated 212,000 infections being averted by 2025 , which translates to an additional $3 \%$ reduction in 
prevalence (4.4\%, compared to a projected $7.3 \%)$, as well as more than $\$ 1$ billion in financial savings [7]. The accelerated scale up, 2014 to 2018, endeavours to circumcise 1.3 million males between 13 and 29 years of age, and with all those ten years and above being eligible for the procedure [8]. Significant developments in 2014 include the initiation of surveillance studies for non-surgical MC (using Prepex) and broadening of the scope of practice for nurses, which allows nurses to lead MC procedures and eases human resource constraints facilities by not requiring a doctor to be present. In the last quarter of 2014, there was also a move from forceps-guided circumcision method to dorsal slit for adolescents following a caution from WHO [9].

However, the voluntary nature of the program demands innovations for demand creation, to accelerate the pace towards the national target of 1.3 million male circumcisions [10]. This is an ambitious objective which is attainable; however, its success will require the key players to coordinate and execute efficient, high-quality service delivery, and to employ innovative strategies to recruit all eligible men. The acceptance of VMMC as an HIV transmission prevention strategy is premised on the procedure being perceived, by the clientele, as being safe, relevant to minimal chances of adverse events during and after the procedure [9]. The WHO set $2 \%$ as an acceptable threshold for adverse reactions following circumcisions to which end Zimbabwe has strived, and succeeded in the past, to minimize the risk of going beyond the acceptable limit through a consortium of quality control measures that range from health care workers (HCW) training, supervision and monitoring and evaluation tools [11].

The VMMC program has so far achieved $42 \%$ of its goal of circumcising 1,300,000 Zimbabwean men by the end of 2018 within the targeted $10-29$-year age group. Mashonaland East province has been implementing the VMMC program since 2009 through static and outreach facilities within its districts, using both surgical and non-surgical approaches (prepex) [12], yet has emerged as one of the low performing provinces in the country and has cumulatively scored $38 \%$ as at 31 December 2016. Within the province, per district performance is as shown below (Figure 1).

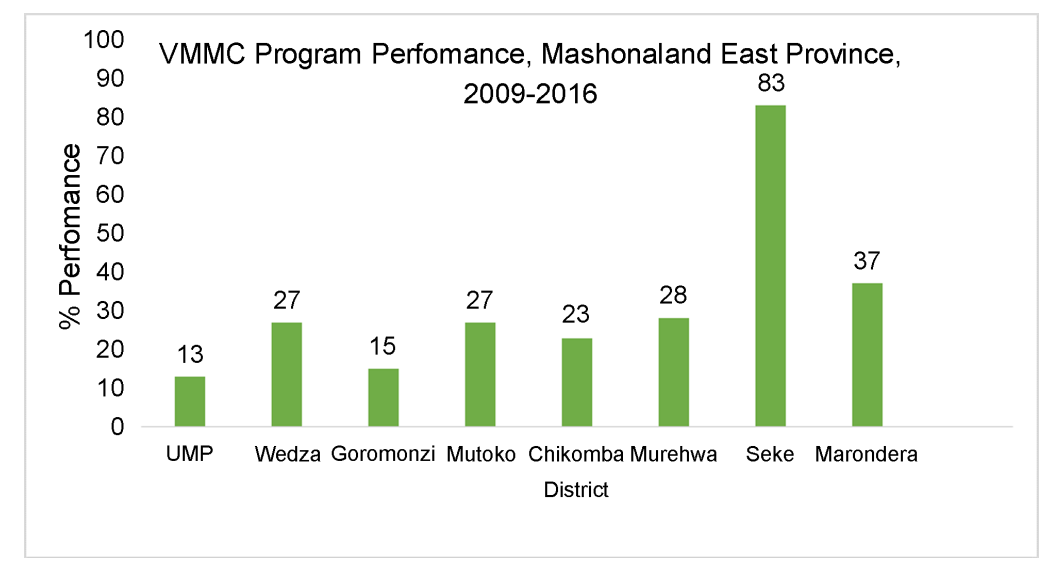

Figure 1. Mashonaland east province VMMC program performance, 2009-2016. 
Notably, Seke and Goromonzi districts, who have a comparable structure and resource supply, registered a markedly varied performance which is a cause for concern.

This performance was on the backdrop of a $2 \%$ (110) adverse event prevalence following circumcision which is above the national rate of $1 \%$ for the same period. Performing below the set target impacts negatively on reducing the incidence of HIV by up to $60 \%$ through VMMC which is part of a comprehensive HIV prevention package. Unless the obtaining situation is mitigated, the risk of failure to achieve the provincial and national targets and even surpass globally acceptable adverse events prevalence of $2 \%$ is likely. The VMMC program in Seke and Goromonzi districts was yet to be evaluated, to inform programming and reform strategies to ensure achievement of the set targets. We, therefore comparatively evaluated this program in Seke and Goromonzi districts, Mashonaland East province, to assist in the planning and safe implementation of the VMMC program in this district.

\section{Methods}

\subsection{Study Design}

A descriptive cross sectional study, using the logical framework approach to conduct a process evaluation was conducted. This study was conducted in two contrasting districts of Mashonaland East province. Seke had the best performance results whereas Goromonzi District had the least, despite comparable geography and support, hence the comparative evaluation. Quantitative data and qualitative key informant interview data were collected concurrently by the investigator after pretesting and relevant readjustments.

\subsection{Sampling Criteria and Sample Size}

The study recruited all 44 trained and active implementers of the VMMC program in Seke and Goromonzi districts. The entire population of nurses and doctors at health facilities offering VMMC were recruited into the study. The District Medical Director (DMO) and the District Nursing officer (DNO) from the district hospitals were purposively recruited as key informants. A total of seven health facilities offering VMMC services in the two districts were visited in Seke and Goromonzi districts.

\subsection{Ethical Considerations}

Permission to conduct the study was obtained from the Mashonaland East Province Institutional review Board. Written informed consent was obtained from all study participants. Confidentiality was maintained by avoiding the use of individual identifying information and keeping all data under a password controlled computer.

\subsection{Data Collection and Management}

Data were collected concurrently between $9^{\text {th }}$ and $20^{\text {th }}$ of January 2017 by the in- 
vestigators. An interviewer-administered questionnaire and checklists were used to assess for inputs, processes, outputs and progress towards outcome evaluation. A desk review of VMMC records was also done. The questionnaires were coded and entered into the computer. Data cleaning was performed to check for errors in data entry prior to analysis.

\subsection{Data Analysis}

Data were analysed using Epi Info ${ }^{\mathrm{TM}}$ Statistical Package version 7. Frequencies and proportions were generated. In-depth data collection was achieved through face to face interviews. Qualitative data was analysed manually for content.

\section{Results}

\subsection{Demographic Characteristics for the VMMC Program, Seke and Goromonzi Districts}

The total number of participants, purposively recruited was 44 , with an equal number coming from the two districts. In total, the majority $(65.9 \%)$ were nurses. Zimbabwe national army (ZNA) nurses constituted 9\% of the participants and were from Seke district alone. The median years of service were 5 years $\left(\mathrm{Q}_{1}=3 ; \mathrm{Q}_{3}=25\right)$ for Seke and 9 years $\left(\mathrm{Q}_{1}=6\right.$; $\left.\mathrm{Q}_{3}=11\right)$ for Goromonzi district. The District Medical officers (DMO's) and their District Nursing officers (DNO's) for the two districts were purposively recruited as key informants (Table 1).

\subsection{Inputs Injected into the VMMC Program, Seke and Goromonzi Districts, Mashonaland East Province, January 2016 to December 2016}

The number of health workers for the VMMC program was $93 \%$ for Goromonzi and $80 \%$ for Seke district, out of the required 15 per district. Both districts had two teams each for VMMC implementation. Goromonzi had two more nurses

Table 1. Demographic characteristics of study participants, Seke and Goromonzi districts, 2017.

\begin{tabular}{ccccc}
\hline \multirow{2}{*}{ Variable } & Category & $\begin{array}{c}\text { Seke } \mathbf{n}=\mathbf{2 2} \\
\text { Frequency }\end{array}$ & $\begin{array}{c}\text { Goromonzi } \mathbf{n}=\mathbf{2 2} \\
\text { Frequency }\end{array}$ & $\begin{array}{c}\text { Totals } \mathbf{n}=\mathbf{4 4} \\
(\%)\end{array}$ \\
\hline \multirow{2}{*}{ Sex } & Male & 6 & 3 & $9(20.5)$ \\
& Female & 16 & 19 & $35(79.5)$ \\
& DMO & 1 & 1 & $2(4.5)$ \\
& DNO & 1 & 1 & $2(4.5)$ \\
& Doctors & 1 & 2 & $3(6.8)$ \\
& Nurses (RGN's) & 13 & 16 & $29(65.9)$ \\
ZNA Nurses & 4 & 0 & $4(9)$ \\
Median years in service & 2 & 2 & $4(9)$ \\
& & 5 & 9 & \\
\hline
\end{tabular}


(14) as compared to Seke which had 12. Both Seke and Goromonzi had one vehicle each for service delivery and none for demand creation. However, Seke district executive provided a second vehicle, from their own district pool, to assist the program. In 2016, both districts received adequate resources for successful implementation of the program with no recorded stock outs throughout the period. No promotional materials were received by the 2 districts in 2016 (Table 2).

\subsection{Processes Involved in Running the VMMC Program in Seke and Goromonzi Districts, Mashonaland East Province, 2016}

Training workshops that were conducted in and outside the province resulted in a balanced number of trained personnel (24) being distributed between the 2 districts. Both districts reported conducting review and planning meetings (4) which were more that the targeted number (3). Notably, both district held 1 out of the provisioned 4 adverse events review meetings, despite Goromonzi having experienced a high number of moderate to severe adverse events following circumcision (55). Inadequate (6/12) mobilisations were recorded in Goromonzi. Notably, Seke received support (3 additional nurses) for outreach. The support of ZNA nurses came from Manyame Airbase (Table 3).

\subsection{Outputs of the VMMC Program, Seke and Goromonzi Districts, Mashonaland East Province, Jan-Dec 2016}

Both districts conducted one more campaign than had been targeted. Seke district circumcised 99.5\% (4716) of their set target whereas Goromonzi managed to circumcise $48.5 \%$ (2372) of their set targets. The targets are varied, according to previous performance and the population base of the district. Moderate to severe adverse events following circumcision recorded were $0.04 \%$ (2) for Seke district and 2.3\% (55) for Goromonzi district. Adverse events are required to be

Table 2. Inputs injected into the VMMC program, Seke and Goromonzi districts, Mashonaland east province, January 2016 to December 2016.

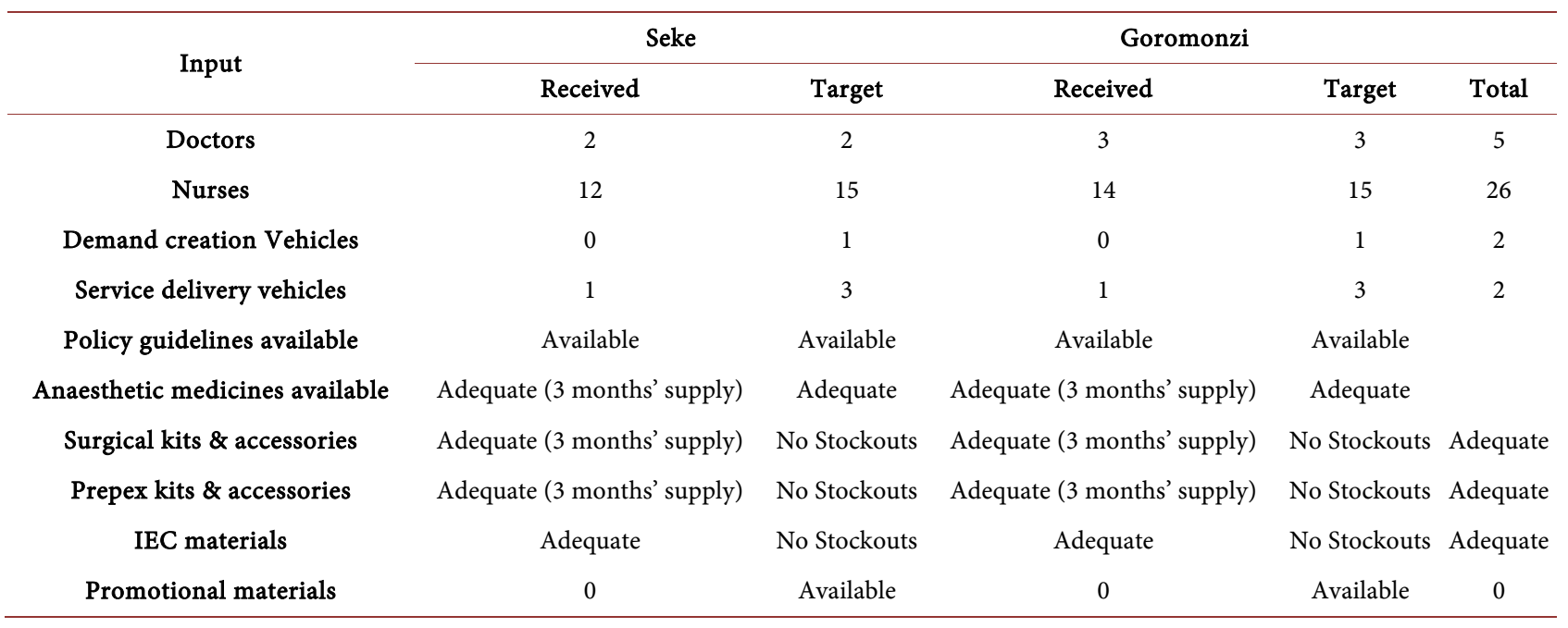


maintained at below $2 \%$ according to the service guidelines. Client follow-ups were done during reviews by both districts in accordance with the set targets (Table 4).

\subsection{Progress towards Achievement of Outcomes of the VMMC Program, Seke and Goromonzi Districts, Mashonaland East Province, December 2016}

Out of their district targets to contribute to 1.3 million circumcisions of HIV-negative males nationally by 2018, from January 2009 to December 2016, Seke district circumcised $83 \%$ of HIV negative, target population males (10 29 -year-olds), realising a discrepancy performance of only $17 \%$. On the other hand, Goromonzi district achieved 15\% circumcisions for the same population and period, realising a discrepancy of $85 \%$ circumcisions to be done by 2018 .

\subsection{Reasons for Above-Average Performance of the VMMC Program, Seke District, Mashonaland East Province, January to December 2017}

Twenty-one (95.5\%) participants in Seke district stated that program ownership by the district management influenced above average performance of the program. Effective coordination mechanisms and implementing motivation by the health workers implementing the program was cited by $22(100 \%)$ and 20 (90.9\%) of the participants, respectively. Fifteen (68.2\%) of the participants

Table 3. Processes involved in running the VMMC program in Seke and Goromonzi districts, Mashonaland east province, 2016.

\begin{tabular}{ccccc}
\hline \multirow{2}{*}{ Processes } & \multicolumn{2}{c}{ Seke } & \multicolumn{3}{c}{ Goromonzi } \\
\cline { 2 - 5 } & Achieved & Target & Achieved & Target \\
\hline Training of Personnel & 12 & 15 & 12 & 15 \\
Review and Planning meetings & 4 & 3 & 4 & 3 \\
Adverse events review meetings & 1 & 4 & 1 & 4 \\
Mobilisations & 12 & Monthly & 6 & Monthly \\
Support for outreach & Given 3 more nurses & & Not given & \\
Cost reimbursement & Delayed & Monthly & Delayed & Monthly \\
\hline
\end{tabular}

Table 4. Outputs of the VMMC program, Seke and Goromonzi districts, Mashonaland east province, Jan-Dec 2016.

\begin{tabular}{cccccccc}
\hline Indicator & \multicolumn{3}{c}{ Seke } & \multicolumn{3}{c}{ Goromonzi } \\
\hline & Done & Target & Performance \% Done & Target & Performance \% \\
\hline Campaigns & 4 & 3 & 133 & 4 & 3 & 133 \\
$\begin{array}{c}\text { Circumcisions done } \\
\text { Adverse events }\end{array}$ & 2716 & 4738 & 99.5 & 2372 & 4890 & 48.5 \\
$\begin{array}{c}\text { experienced } \\
\text { Client follow up }\end{array}$ & Done During Review & 100 & Done During Review & $100 \%$ \\
\hline
\end{tabular}


thought effective mobilisations, whereby Environmental health technicians and ZNA nurses conducted community mobilisation could have enhanced program performance in Seke.

\subsection{Reasons for Underperformance of the VMMC Program, Goromonzi District, Mashonaland East Province, January to December 2017}

The majority of the participants (90.9\%) in Goromonzi stated that late payments by the sponsoring partner were the major reason for the poor performance of the program. Lack of effective coordination of the VMMC activities within the district was identified as the second $(77.3 \%)$ most prevalent reason for the underperformance of the program. Weak mobilisation strategies and inadequate transport were the least common reasons for program performance at $50 \%$ and $36.4 \%$ respectively. The fact that VMMC is not integrated into the health facility departments was cited by $63.6 \%$ of the participants as one of the reasons for poor performance.

\section{Discussion}

\subsection{Adequate Resource Supply}

Resource supply for execution of VMMC was adequate, with no reported stock outs. However, this did not translate to standard performance for Goromonzi, contrary to the findings by Gray et al. 2004 in Uganda where a direct relationship between adequate resourcing and optimal performance was observed [4]. The two districts were comparable regarding material resource supply for the period reviewed, the number of teams implementing the program, geography and administration. The two districts were financially supported from inception by the same partner (PSI) and had disbursements done simultaneously.

\subsection{Seke District Received Assistance from ZNA Nurses}

The fact that Seke received assistance from ZNA nurses for their onsite and outreach activities put them at an advantage over Goromonzi. Seke district received additional 3 nurses from Manyame air base and this provided human resources, solely for the purpose of conducting circumcisions. Health workers implementing the program are full employees at their respective institutions and need to balance routine responsibilities and VMMC activities. Though Goromonzi enjoyed an increased number of trained doctors and nurses over Seke district, however, this marginal advantage did not translate to better performance of the program. Adequate human resource supply was identified as a key aspect to program success, according to Fleming et al. (2008) in Brazil [13].

\subsection{Lack of Promotional Materials for Both Districts}

The absence of promotional materials in both districts poised a disadvantage in both districts. This was consistent with findings by Weiss et al. (2011) which in- 
dicated the key role of promotional material in demand creation in a metaanalysis for 4 southern African countries [12].

\subsection{Weak Mobilisation Strategies in Goromonzi}

Out of a target of 20, Goromonzi had only 6 active community-based mobilisers who were not evenly distributed within the catchment community. Other villages are reported to have more than 1 cadre whilst others do not have. This resulted in weak mobilisation activities. Community-based mobilisers are an effective strategy that utilises peers within the same community to mobilise them for the program and this is working effectively in Seke.

\subsection{Higher Incidence of Adverse Events in Goromonzi}

High incidence rate of moderate to severe adverse events following circumcision in Goromonzi suggests that not only is the district failing to circumcise clients as expected, but that the few being circumcised are not being done so in accordance with the set standard operating procedure. Goromonzi conducted one adverse event review meeting despite unacceptably high incidences. Above $2 \%$ adverse moderate to severe adverse events following circumcision is a serious cause for concern, particularly with the backdrop of poor performance.

\subsection{Limited Evidence of Program Ownership in Goromonzi}

Though the 2 districts received one vehicle each for both service delivery and demand creation activities, Seke district executive provided the second vehicle in support of VMMC activities which was not the case with Goromonzi. This revealed program ownership on the part of Seke. Goromonzi cited inadequate transport availability as one of the hindrances to program success in. The success of any program is largely depended on the buy-in of the community and its leadership. Some of the interviewed members of the Goromonzi District health executive (DHE) were not aware of the VMMC activities and available resources such as the partner provided the vehicle. This is also supported by $63.6 \%$ of the participants who cited lack of program ownership as one of the reasons for poor performance.

\subsection{Lack of Coordination in Goromonzi}

Inadequate coordination, as evidenced by minimal consultation between the district VMMC coordinator and the DHE in Goromonzi and suboptimal sharing of the available vehicle between the two teams worked against the program. Members of the DHE interviewed revealed that they received no feedback from the coordinator when the team went out for outreach or campaigns. They, therefore, remained unaware of the success and failures of the program. The ideal situation is for the district coordinator, appointed by the DHE, to always update on VMMC plans as well as yields following outreach and campaigns. 


\subsection{Low Implementing Motivation in Goromonzi}

A generally demotivated attitude by the health workers, cited by $54.5 \%$ of the participants was apparent too. The chronic underperformance did not seem to trigger concern as evidenced by the 2 teams in Goromonzi not doing much to explore solutions. Given the poor results, it was expected that the district should be holding crisis meetings in order to identify drawbacks and explore ways to enhance performance.

\subsection{VMMC Not Integrated into Routine Facility Activities in Both Districts}

VMMC is implemented by health workers who have other activities that they need to prioritise following allocation on a daily basis. VMMC is not recognised as part of the service centre departments that is given personnel. This seemed to work against the program in both districts since workers would need relief from routine duties to attend to VMMC clients. In a study by Ashengo et al. in Tanzania, integration of VMMC into key health facility activities through the designation of the facility as a department yielded positive results in regard to resource supply, both human and material [14].

\subsection{Below Average Outputs for Goromonzi District}

The outputs of the program reveal a marked variation between the 2 districts. Whereas Seke performed exceptionally well, scoring 99.5\% circumcisions during the year 2016, Goromonzi posted $48.5 \%$ success from their set target. The targets were set considering the population denominator and not in consultation with the implementers. The program aims to circumcise 1.3 million HIV-negative males in order to realise $85 \%$ reduction in HIV transmission. The criterion to allocate provinces and districts population specific targets was applied in order to realise the national goal.

\subsection{Progress towards Achieving Outcomes}

Considering program performance from inception in 2009 to date, and its mission to circumcise 1.3 million HIV-negative males between 10 to 29 years of age, Seke is on course at $83 \%$. A different situation is obtaining with Goromonzi which has achieved only $15 \%$ of their set target. If this situation is not mitigated, Goromonzi is set, not only to miss their district target but to also impact negatively on the provincial as well as the national performance. This revelation, therefore, points to an urgent need to address the situation in Goromonzi to enhance performance.

The most common reason cited by participants from Goromonzi for the underperformance of the VMMC program was a late disbursement of payments. On analysis, this reason is invalidated by the fact that disbursements were simultaneously done for Seke district as well. The funds are from the same partner at similar rates. 


\section{Study Limitations}

Findings from this study should be interpreted in light of its limitations in generalizability to the larger population since our evaluation was focused on circumcisions done for 10 - 29-year-old HIV negative males, not all circumcisions. This is the target population being circumcised to achieve the program objective to prevent up to 3.4 million new HIV infections by 2025 in Zimbabwe. As such, the study still provides important insight regarding VMMC program implementation in Zimbabwe.

\section{Conclusions}

The 2 districts were equitably allocated human and material resources during the period under review. Adequate material resource supply did not correlate with program performance and a wide discrepancy in performance occurred between comparable districts. Identified reasons for underperformance in Goromonzi were poor coordination, lack of active leadership involvement in planning and execution, low implementing motivation and weak mobilisation strategies, whereas effective demand creation and coordination, manpower boost and leadership support enhanced VMMC program performance for Seke and was therefore recommended for Goromonzi. Robust demand creation strategies were suggested for both districts.

As part of the public health actions taken as a result of this study, we discussed the challenges faced by Goromonzi with the District Health Executive team (DHE) and suggested mitigatory strategies. Feedback and suggestions were given to the provincial and the national VMMC coordinators. Feedback was also given to the districts the province.

\section{Competing Interests}

The authors declare that they have no competing interests.

\section{Acknowledgements}

I would like to express my sincere gratitude to my field supervisor, Dr O. Mugurungi for his prodding throughout the study, and to the VMMC implementing personnel in Seke and Goromonzi districts for their support. Special thanks go to the staff in the Department of Community Medicine and MPH field office for all the help they rendered. We would also like to express our profound gratitude to Centers for Disease Control (CDC) Zimbabwe for funding and technical input. Many thanks go to all participants for their consent to participate in the study. Last, but not least, I would like to thank my family for social support throughout the project.

\section{References}

[1] World Health Organization (WHO) (2007) Joint United Nations Programme on HIV/AIDS (UNAIDS). New Data on Male Circumcision and HIV Prevention: Policy and Programme Implications. WHO, Geneva. 
http://www.malecircumcision.org/programs/male circumcision programmes.html

[2] Auvert, B., Taljaard, D., Lagarde, E., Sobngwi-Tambekou, J., Sitta, R. and Puren, A. (2005) Randomized, Controlled Intervention Trial of Male Circumcision for Reductionof HIV Infection Risk: The ANRS 1265 Trial. PLoS Medicine, 2, e298. https://doi.org/10.1371/journal.pmed.0020298

[3] Bailey, R.C., Moses, S., Parker, C.B., Agot, K., Maclean, I., Krieger, J.N. and NdinyaAchola, J.O. (2007) Male Circumcision for HIV Prevention in Young Men in Kisumu, Kenya: A Randomised Controlled Trial. The Lancet, 369, 643-656. https://doi.org/10.1016/S0140-6736(07)60312-2

[4] Gray, R.H., Kigozi, G., Serwadda, D., Makumbi, F., Watya, S., Nalugoda, F., et al. (2007) Male Circumcision for HIV Prevention in Men in Rakai, Uganda: A Randomised Trial. The Lancet, 369, 657-666. https://doi.org/10.1016/S0140-6736(07)60313-4

[5] UNAIDS/WHO (2011) Joint Strategic Action Framework to Accelerate the ScaleUpof Voluntary Medical Male Circumcision for HIV Prevention in Eastern and Southern Africa. UNAIDS/WHO, Geneva.

[6] World Health Organization (2013) Use of Devices for Adult Male Circumcision. In: Masese, R.J., et al., Eds., 55 Public Health HIV Prevention Programmes. http://www.who.int/hiv/pub/malecircumcision/devices conclusions/en/index.html

[7] Baker, P., Dworkin, S.L., Tong, S., Banks, I.S. and Yamey, G.T. (2014) The Men's Health Gap: Men Must Be Included in the Global Health Equity Agenda. Bulletin of the World Health Organization, 92, 618-620. https://doi.org/10.2471/BLT.13.132795

[8] Lissouba, P., Taljaard, D., Rech, D., Dermaux-Msimang, V., Legeai, C., Lewis, D., et al. (2011) Adult Male Circumcision as an Intervention against HIV: An OperationalStudy of Uptake in a South African Community (ANRS 12126). BMC InfectiousDiseases, 11, 253. https://doi.org/10.1186/1471-2334-11-253

[9] Weiss, H.A., Dickson, K.E., Agot, K. and Hankins, C.A. (2010) Male Circumcision for HIV Prevention: Current Research and Programmatic Issues. AIDS (London, England), 24, S61-S69. https://doi.org/10.1097/01.aids.0000390708.66136.f4

[10] Njeuhmeli, E., Forsythe, S., Reed, J., Opuni, M., Bollinger, L., Heard, N., et al.(2011) Voluntary Medical Male Circumcision: Modelling the Impact and Cost of Expanding Male Circumcision for HIV Prevention in Eastern and Southern Africa. PLoS Medicine, 8, e1001132. https://doi.org/10.1371/journal.pmed.1001132

[11] Ministry of Health and Child Care Zimbabwe (2010) Draft Strategy for Safe Male Circumcision to Scale-Up to Support Comprehensive HIV Prevention in Zimbabwe.

http://www.emtct-iatt.org/wp-content/uploads/2016/01/Zim Accelerated-StrategicOperational-Plan VMMC-2014-2018.pdf

[12] Williams, B.G., Lloyd-Smith, J.O., Gouw, E., Hankins, C., Getz, W.M., Hargrove, J., et al. (2006) The Potential Impact of Male Circumcision on HIV in Sub-Saharan Africa. PLoS Medicine, 3, e262. https://doi.org/10.1371/journal.pmed.0030262

[13] Fleming, D.T. and Wasserheit, J.N. (2008) From Epidemiological Synergy to Public Health Policy and Practice: The Contribution of Other Sexually Transmitted Diseases to Sexual Transmission of HIV Infection. Sex Transmission Infect, 75, 3-17. https://doi.org/10.1136/sti.75.1.3

[14] Ashengo, T.A., Hatzold, K., Mahler, H., Rock, A., Kanagat, N., Magalona, S., et al. (2014) Voluntary Medical Male Circumcision (VMMC) in Tanzania and Zimbabwe: Service Delivery Intensity and Modality and Their Influence on the Age of Clients. PLOS ONE, 9, e83642. https://doi.org/10.1371/journal.pone.0083642 


\section{Abbreviations}

$\begin{array}{ll}\text { AE } & \text { Adverse Events } \\ \text { EIMC } & \text { Early Infant Male Circumcision } \\ \text { HCW } & \text { Health Care Workers } \\ \text { HIV } & \text { Human Immunodeficiency Virus } \\ \text { HSO } & \text { Health Studies Office } \\ \text { HTC } & \text { HIV Testing and Counselling } \\ \text { M\&E } & \text { Monitoring and Evaluation } \\ \text { MC } & \text { Male Circumcision } \\ \text { MCD } & \text { Male Circumcision Days } \\ \text { MOHCC } & \text { Ministry of Health and Child Care } \\ \text { PITC } & \text { Provider Initiated Testing and Counselling } \\ \text { PSI } & \text { Population Services International } \\ \text { STI } & \text { Sexually Transmitted Infections } \\ \text { VCT } & \text { Voluntary Counselling and Testing } \\ \text { VMMC } & \text { Voluntary Medical Male Circumcision } \\ \text { VFP } & \text { VMMC Focal Persons } \\ \text { VMMC } & \text { Voluntary Medical Male Circumcision } \\ \text { WHO } & \text { World Health Organization }\end{array}$

\section{Scientific Research Publishing}

Submit or recommend next manuscript to SCIRP and we will provide best service for you:

Accepting pre-submission inquiries through Email, Facebook, LinkedIn, Twitter, etc. A wide selection of journals (inclusive of 9 subjects, more than 200 journals)

Providing 24-hour high-quality service

User-friendly online submission system

Fair and swift peer-review system

Efficient typesetting and proofreading procedure

Display of the result of downloads and visits, as well as the number of cited articles

Maximum dissemination of your research work

Submit your manuscript at: http://papersubmission.scirp.org/

Or contact ojpm@scirp.org 